\title{
Complejidad epistemológica de las artes visuales: su pensamiento $y$ proceso de creación discursiva
}

\author{
Ronald Gerardo Rivera Alfaro \\ Centro de Estudios Generales \\ Universidad Nacional, Costa Rica \\ ronaldrive@gmail.com
}

\begin{abstract}
La idea de un solo corte que dividiera de una vez y en un momento dado todas las formaciones discursivas, interrumpiéndolas en un solo movimiento y reconstituyéndolas según las mismas reglas, es una idea inconcebible

Michel Foucault
\end{abstract}

\begin{abstract}
Resumen
Las ideas de simplificación y orden son las constantes epistemológicas de la modernidad; su ataraxia creativa redujo el impacto de las artes visuales a meras narraciones decorativas que interpretan subjetivamente el mundo. La subsunción de axiomas claves del dogmatismo científico en la figura epistemológica moderna como la perspectiva, la luz, el tiempo y el espacio han sido objeto de estudio de las artes visuales antes que el método científico distanciara, con tintes abismales, las ciencias y las humanidades. La complejidad en los procesos discursivos de las artes visuales son tan solo un vistazo de la contingencia e incertidumbre del mundo social.
\end{abstract}

Palabras clave: artes visuales, creación, innovación, blanco, fin del arte.

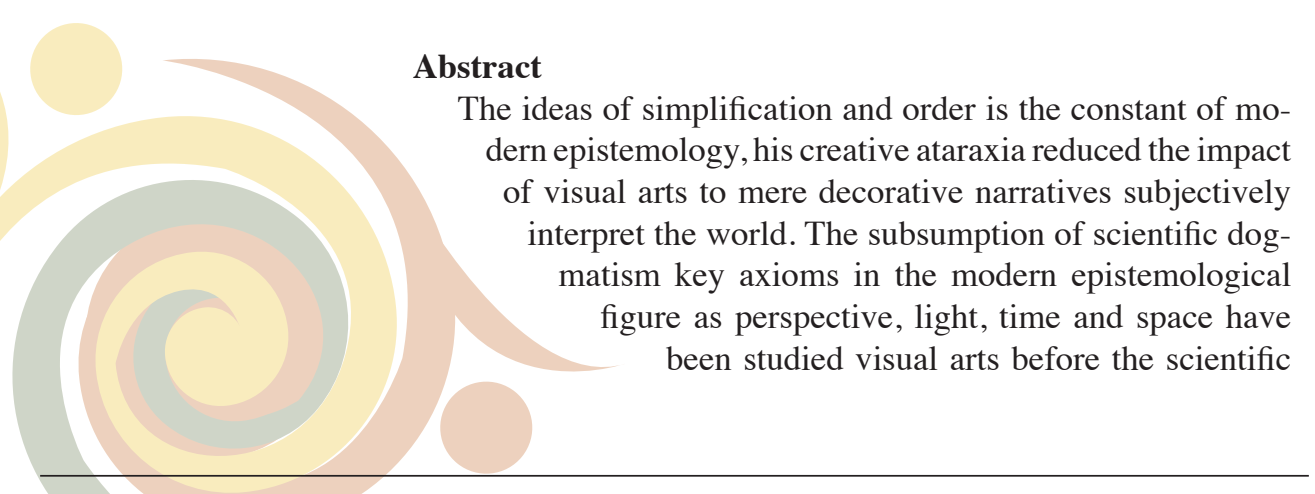


method alienate, tinged with abysmal, sciences and humanities. The complexities of the discursive processes of the visual arts are just a glimpse of the contingency and uncertainty of the social world.

Keywords: visual arts, creation, innovation, white, end art.

$\mathrm{E}$ 1 discurso artístico, fuente de interpretaciones y narraciones históricas, ha sido plataforma epistemológica para transformaciones-dislocaciones-revoluciones científicas, transformando las bases de los imaginarios sociales insertos en un universalismo inteligible de racionalidades que no visibilizan las irracionalidades del pensamiento occidental moderno.

La idea de un conjunto ordenado en secuencias discursivas a, b, c, d provee un orden registral que alinea la comunicación visual por medio del pensamiento dominante o imperante en el espectro político-económico general, de manera que la producción cultural puede ir y venir sin contraponer otros modelos teóricos. Este mecanicismo científico moderno de la previsibilidad de las imágenes y mescolanza de discursos "universales" no entiende la lógica de la interculturalidad y la transdisciplinariedad que pueden aportar las artes visuales y su visibilización de conflictos paradigmáticos (contradicciones internas) en co-existencia con los conflictos subparadigmáticos (los excesos y déficits) (Santos, 2003, p. 190).

Es por eso que introduciremos las contradicciones del funcionamiento positivizado de las "ciencias", con respecto a la necesaria "fluctuación" de las artes visuales y su aporte a la teoría social, su uso y alejamiento concomitante en la estricta secuencia: exponente referencial-simbolismo, esto, aunado a breves ejemplos en la historia del arte de ¿cómo el dinamismo sociocultural y la apropiación de los avances científicos permiten reorganizar nuevas formas discursivas de mirar el mundo?, para finalizar con la crítica a posturas que inducen "la muerte" o "finitud" del arte.

\section{Innovación de significados: las artes}

Las artes como medios, herramientas y traductores del pensamiento son sacadas de la expresividad del ser humano como medio evolutivo del discurso histórico, el cual cambia constantemente su habla y con ello sus dispositivos semiológicos para generar identidad. 
En este sentido, la mutua determinación de significados (Rojas, 2006, p. 206) aviva la lógica de Thomas Kuhn, la cual entiende que el cambio en la estructura del pensamiento posee un paralelismo evidente, "tanto en el desarrollo político como en el científico, el sentimiento de mal funcionamiento que puede conducir a la crisis es un requisito previo para la revolución" (Kuhn, 1971, p. 150).

Así, la pluralidad y complejidad de los diferentes discursos -críticos- entienden que el uso de la razón no está determinado por "un" método que omita la incertidumbre, siendo este desajuste, contradicción y ambigüedad de la doctrina meramente lógica (Russell en Ayer, 1986, p. 58) que establece un orden (a, b, c), y legitima los conceptos y las proposiciones científicas de una sintaxis lógica del lenguaje científico.

Este sofocamiento epistemológico inicia en los años treinta gracias a los aportes del llamado "Círculo de Viena", el cual acuñó el término positivismo lógico o bien filosofía analítica, en la que se revierten discursos falseando sus postulados primigenios, al entender el proceso de creación de pensamiento como la ejecución de un método cuya posibilidad existe por la dependencia de los acontecimientos determinados -hechos-propiedades- empíricamente, dejando en contingencia los sinsentidos de un paradigma en crisis.

Si bien la intencionalidad discursiva abre el espectro comunicacional, para Bertrand Russell la analogía de la palabra con el objeto no se refiere, en primera instancia, a la identidad del objeto, por lo que la abstracción del discurso hace más simple el pensar sobre la palabra que sobre el objeto, aunque este vaya más allá de las relaciones de dos términos.

El espectro analítico interviene, necesariamente, desde un punto de vista más complejo; un nuevo método -que no puede ser método ${ }^{2}$ - reflexivo interviene en la reducida idea de Russell sobre la palabra y el objeto. El otrora aspecto crítico se fundamenta en el conocimiento de las artes visuales como una ficción del

1 El Círculo de Viena surge entre 1920 y 1930, cuando Moritz Schliz se ocupó de la Cátedra de Filosofía en la Universidad de Viena junto a Carnap, Neurath, Feig, Waismann, entre otros, dando inicio a un proceso analítico de temas en común comenzando con la publicación de un manifiesto titulado El punto de vista científico del Círculo de Viena.

2 Se hace referencia al término método, aunque no deba entenderse como tal. Un método determina procedimientos, estrategias y pasos lógicos por seguir; el análisis crítico busca, por el contrario, dilucidar la irracionalidad de lo racionalizado donde, necesariamente, se debe intervenir en el método y sus determinaciones. 
conocimiento mismo, como una subjetividad crítica de la realidad que relaciona el mundo y su lenguaje, sin importar su multiplicidad de significaciones.

Lo que el positivismo lógico denomina como "error" o "confusión filosófica", las artes visuales, al igual que el resto de espacios artísticos (la música, la literatura), lo miran como recreación del habla, del mirar y entender transdisciplinario de un modelo que equipara el universo real con las proyecciones -fundamentalmente críticas- de las relaciones socioculturales con la subjetividad (Adorno, 1969).

Un efecto peculiarmente tangible es la función histórico-cultural que las narraciones artísticas entretejen en una infinitud de posibilidades que recrean la identidad cultural y sugestionan los atisbos del acontecer general. Esa inmensidad de lenguajes y discursos no pueden, desde ninguna circunstancia, entenderse como imágenes acríticas de la realidad social.

El asocie complejo y connotativo de tendencias y metáforas que implican cambios ideológicos ${ }^{3}$ rompe con la linealidad denotada del dogmatismo positivista, que posiciona la teoría social clásica como presente y futuro de la humanidad.

La crítica que Adorno realiza sobre la autonomía del ser humano y su concepto de totalidad $^{4}$ aviva la crisis de las Ciencias Sociales con respecto a la ceguera científica, la cual es incapaz de reconciliar la libertad del ser humano con los procedimientos e institucionalidad académica. Contrario a esto, las artes revitalizan, con abstracciones figurativas y no figurativas de la realidad, los espacios de diálogo y didáctica intercultural. Así, "las obras de arte se salen del mundo empírico y crean otro mundo, con esencia, contrapuesto al primero, como si este nuevo mundo tuviera consistencia ontológica" (Adorno, 1969).

El concepto de arte viene y va, se aleja pero también aporta nuevas concepciones históricas que le favorecen en su separación contra lo "meramente existente" (Adorno, 1969) y permiten que las diferentes constelaciones históricas perneen su quehacer estético de pensamiento.

3 El término ideología no debe entenderse como un simple conglomerado de ideas; por el contrario, la ideología existe cuando aquella es en los hechos, es decir, una ideología solo puede ser considerada como tal si en efecto su fundamento se encuentre materialmente contenido en las relaciones humanas.

4 La totalidad en Adorno hace referencia a un materialismo histórico que funciona de manera heterogénea, donde cada parte desempeña una función para el mantenimiento de la unidad del todo. Así, la crítica al principio de la symploké es fundada en la totalidad abstracta, la que establece un todo conectado con todo o la nada con nada, en ese sentido, no podría existir el conocimiento. 
A inicio del siglo XX, las corrientes modernas de pensamiento seguían con la lógica cartesiana de avanzar gradualmente el pensamiento y subsumirse en una deducción propia de la matemática y, por tanto, referenciada de orden, en el que todas las partes estén alineadas y sin contradicciones. Este principio de "armonía", superfluo y dogmático, encierra a priori el alejamiento en el proceso creativo que las artes donan a la historia, como medio crítico de mirar el mundo; de allí que el tiempo en el arte valide estilos y tendencias, pero al mismo tiempo esté modificando el pasado y programando el futuro, a lo que estaríamos apuntando a un pasado presente al ejecutar un presente-futuro.

\section{Excursus que evocan hacia el blanco: la totalidad}

De estilos a tendencias, el tiempo de innovación y creación artística se ve recortado, en gran medida, por el dinamismo sociocultural y los avances científicos que permiten reorganizar nuevas formas discursivas de pensar e interpretar la naturaleza y el ser humano.

Los amplios estilos artísticos, desde el Renacimiento hasta el Rococó, fueron parte de grandes cambios en la vida política y social del planeta. La homologación del hombre con Dios era parte de un pensamiento "antropocéntrico", sumergido en los preceptos aristotélicos, es decir, la escolástica, donde su espíritu situaba al hombre en el centro del universo y, por lo tanto, sus posibilidades en esta vida se acrecentaban gracias a la unión de temas sacros con imágenes materiales del ser humano, como la desnudez joven o el retrato.

La creación de la perspectiva -propia de la ciencia moderna del siglo XVI, pero creada por las artes renacentistas-, es tomada como parte de este nuevo re-nacer del "espíritu" humano. El dominio sobre la naturaleza y el creciente auge de dioses paganos habían atraído la atención de un mundo corpóreo distinto del mundo del medioevo.

Por lo tanto, es de notar con facilidad que los esquemas estéticos no eran tomados al azar; estos períodos marcaron para siempre no solo el arte sino las demás ciencias. La razón, el nacimiento de la ciencia como búsqueda de leyes y el arte como lenguaje clave para acceder al poder ${ }^{5}$ eran parte del esquema sociológico que se desarrollaba en los siglos XV al XVII.

5 Los Medici, coleccionistas de arte del siglo XV, específicamente, Lorenzo de Medici, conocido como "il Magnifico", convirtió la ciudad de Florencia en una potencia política y comercial de toda Italia. Algunos de sus protegidos brindaban esa estela de poder necesaria para codearse con los príncipes de la época. 
El entendimiento e interpretación sin coacción reconoce que el arte no podía mantener un método de creación uniforme y, mucho menos, intentar subsumir el proceso de creación ontológica del arte por motivos "supremos" de intereses no seculares. Así, la desvinculación del arte con la teología y su idea de la salvación en siglos anteriores dio cabida para que la constelación explosiva e irreverente del lenguaje plástico brindara una serie de claves inmanentes en la conformación de nuevas identidades.

Desde los discursos sociológicos y antropológicos, que sostienen el proceso de creación metafórica del arte, como referente histórico de realidades, ligaban la técnica, la imagen y su retórica con la diversidad simbólica de los "objetos" encontrados, los cuales no siempre vienen acompañados de una elocuencia o razón empírica universal, ejemplo de ello es que en el siglo XX se da una explosión de tendencias que interpretan y visualizan problemas de conciencia histórica sin tener que coincidir con la forma ni el lenguaje plástico. De esta manera, el uso del color, de las formas básicas de la geometría, de las convergencias de nuevas perspectivas, la fotografía y el cine, brindan un amplio margen de elementos que nos llevan a un punto de encuentro: la totalidad del significado en un mundo de múltiples referencias significantes.

En este sentido, el blanco ${ }^{6}$ posee un valor referencial que instaura la identidad del todo. A continuación analizaremos la metáfora del blanco y sus dos opciones materiales, como pigmento -también se podría referir como luz- y como forma.

Si el exponente material -dibujo, escultura, acuarela- posee su propio referente y solo a través de él se puede comprender el mundo y su vida, cada cuerpo debe ser el exponente de su propio referente, así la semiótica cobra vida. Por lo que el "ver" implica la existencia material de un objeto y ese objeto involucra que veo y su valor referencial podría remitir a varias explicaciones que, en primera instancia, serían material de expresión -el discurso- y medio de expresión -acto de comunicación.

A continuación, un breve ejemplo de cómo los modos de expresión -formas y colores- están acompañados en clave de una referencialidad cultural.

6 Se habla del blanco como un tono que refleja la totalidad de la infinitud de los matices. Todos juntos forman el blanco. 


\section{Colores y formas se unen}

La fotografía y el cine existen gracias a las tecnologías que reconocen el efecto reflexivo de la luz perfeccionado mediante los aditivos del color y el movimiento. Su desarrollo exponencial es tan solo parte del uso científico que el arte, de manera contingente, le da a sus propias formas de creación.

La pintura, la escultura y el grabado, por citar solo algunos ejemplos, se mantienen en un espectro más tradicional de creación, sin que esto implique su estancamiento. La innovación en los procesos de elaboración está en constante cambio, debido a que existe una tensión entre el contenido y la forma, la cual atrae y renueva formas de expresividad palpable en sus montajes y combinaciones estéticas. Lo que en él hay de específicamente artístico procede de algo distinto: de este algo hay que inferir su contenido: y solo este presupuesto satisfaría las exigencias de una estética dialéctico-materialista (Adorno, 1969).

Un ejemplo, el fauvismo, a principios del siglo pasado mostraba cierta rebeldía en sus formas dando prioridad al color; el mismo efecto de la luz sobre la forma contempla, fundamentalmente, una innovación espacial y temporal de las imágenes y de su entorno. Una visión simple y acrítica del fauvismo sería contraria a las posibilidades interpretativas que el arte ofrece a la estética general. Ese trazo "impulsivo" que, paradójicamente, no podría serlo abre la ventana a un siglo donde la inteligibilidad científica obstaculiza una "verdadera" interpretación del arte y sus lenguajes.

El pintor "fauve" conoce la lógica fragmentaria de la luz y su disolución visual binocular con respecto al material; el lugar donde se encuentra el objeto y su incidencia con el tiempo permite abordar un lenguaje plástico que necesita manejar con gran dinamismo, asimismo, el color, sus combinaciones y grados de reflexión.

La lógica fauvista es contraria a la impresionista, la cual diluye una pared con el cielo, y fusiona los ventanales de la catedral de Rouen y las vigas de la estación de Saint-Lazare con el infinito paisaje; pero ambos reconocen, al mismo tiempo, un mundo alternativo donde no se agotan las dimensiones de la vida y de la muerte, de la inmensidad y de lo infinitivamente pequeño. El color danza sobre el cuerpo y desmantela el materialismo histórico de la percepción conservando su crítica sobre la vida, su contingencia e incertidumbre. 
En el caso de América Latina, esa inteligibilidad de la razón transportada por las infinitas posibilidades del lenguaje encuentra un punto azaroso en medio de tanta diversidad. Armando Reverón es el ejemplo ideal para presentar la participación del individuo en su mundo cultural, su mundo histórico y, con ello, mostrar lo que se quiere como lo que no se quiere, en una disociación material del mundo, la arbitrariedad y la historia. Su lógica lo lleva a encontrar el blanco sobre blanco, donde color y forma se unen gracias al espacio-tiempo, a la percepción y a la reflexión sin límites inductivos.

Blanco sobre blanco es una obra que es reconocida desde la tendencia vanguardista suprematista, donde Malévich, su creador, centra su atención en formas geométricas básicas en una reducción de elementos pictóricos que, contradictoriamente, abarcan todas las formas posibles. Un sistema completo de construcción donde el "orden" universal está determinado por una rigidez conceptual, que desea llegar a la totalidad por medio de una estructura de pensamiento lineal.

El blanco se ha convertido en la metáfora del discurso político que sustenta la falsa promesa del progreso a través del orden mundial. Orden y progreso son la base de la teoría social clásica en la cual Comte expone su física social, por medio de la aplicación del método científico.

Es la intencionalidad y deber del arte explicar los complejos procesos sociales por medio de una epistemología, que se adhiere a una hermenéutica histórica fundada en el lenguaje.

Tanto Malévich como Reverón, en espacios culturales distintos y en un mismo tiempo, interpretan, anuncian y esclarecen la contingencia universal de la diversidad del sujeto, sin tener que apropiarse sacramente del método científico. Se lo apropian, entienden y analizan los aportes teóricos de la física, la matemática, la sociología; pero, al mismo tiempo, evocan un pensamiento crítico sobre el mundo, sobre sus formas e interpretaciones de mirar esas formas que, a la postre, son imágenes que establecen un imaginario social instituyente.

Estás proposiciones no tienen por endereza productiva un fin; su validez y permanencia radica en la perpetuidad de la interpretación y en el aporte para generar y ser análisis crítico de una racionalidad instrumental. 


\section{"Fin" y "finitud" del arte}

El filósofo alemán Hegel, en su texto "Lecciones de estética" de los años 18321845 , sugiere la pregunta ¿debe tratarse el arte como una ciencia?, a lo cual el filósofo remite varias consideraciones importantes por repasar. La primera, es dejar el arte como instrumento decorativo y, por lo tanto, como espacio de distracción, debido a que su creación no puede ser libre, atada a un juego servil de intereses. En cambio, la segunda consideración es sobre el arte libre, alejado de determinaciones causales que procuran para Hegel una tarea suprema (Hegel, 1989, p. 14) siendo el legado histórico uno de los contenidos más ricos de las instituciones y representaciones internas de los pueblos.

Ante estas consideraciones o premisas genealógicas, la libertad del pensamiento, con sensibilidad y expresividad connotativa del mundo, debe tratar científicamente el arte como fuente de narraciones necesarias para reordenar la historia del pensamiento junto a sus tensiones y desgarramientos de la misma producción científica. La estética hegeliana del contenido ha reconocido ese momento inmanente del arte que es su ser otro y ha sobrepujado a la estética formal, que aparentemente opera con un concepto más puro del arte (Adorno, 1969).

Igualmente, la consideración histórica, primordial para el desenvolvimiento y el desarrollo del artista, requiere de una comprensión "general" para el esclarecimiento a posteriori de la obra.

Por lo tanto, vale la pena introducir el tercer punto de vista hegeliano ante la obra de arte, y es su finalidad, no en el sentido de finitud sino como intención; así, la imitación de la naturaleza como aspecto formal entrelazado, como destreza plástica, induce a que el contenido del arte es "llevar a nuestro sentido, a nuestra sensación y nuestro entusiasmo todo lo que tiene cabida en el espíritu" (Hegel, 1989, p. 46), por lo que el arte quedará a disposición de ofrecer una referencialidad de los fenómenos sociales, capaz de comprender la miseria y el delirio, de establecer un poder que contenga la vida en una externalidad formal, por lo que se concluye que el fin hegeliano del arte es instruir.

En cierto sentido, hemos descrito cómo desde las palabras y los colores se atraen las formas y los espacios y, si bien el arte es por creación -proceso creativo- reaccionaria, en ninguna circunstancia es caótico, pero sí contingente y complejo. 
Seguidamente, las narraciones de los noventas sobre el fin, en sentido de "caída" del arte.

A finales de los años noventa, Arthur Danto junto con Hans Belting establecieron el fin del arte como una sensación vivida y causal cuando las condiciones narrativas y de producción de las artes visuales cambian; ellos no sentencian, aunque persiste una negación al respecto sobre la muerte del arte, sobre el fin de una narrativa, pero, al mismo tiempo, sin ser la narrativa el tema. Su epitafio artístico se apodera del enunciado del movimiento dadaísta de Berlín que "proclamó la muerte del arte" (Danto, 1999, p. 27).

Aún y cuando la Modernidad marca un punto de quiebre en la producción y en el entendimiento del arte, gracias a un cambio radical, la representación de la naturaleza cambia y el tema es el mismo arte, la matriz del pensamiento artístico plantea un giro discursivo que no agota o concluye con ningún tipo de narrativa. La idea de crisis paradigmática, proveniente de Khun, no es necesariamente aplicable al desarrollo estético, por lo tanto, perceptivo de las imágenes.

Se visualiza una etapa de cambio, y es solo desde el cambio como revolución epistemológica y nunca como muerte, la que puede sostenerse en medio de gritos reaccionarios y de pesimismo cultural, como lo expone Theodor. Adorno, intenta dar explicaciones concretas del porqué el arte se subleva continuamente.

El mimetismo del arte premoderno no es causa del desarrollo abstracto del Modernismo. La idea de fin como límite -así lo entienden Danto y Belthing- no es aplicable en el arte, debido a que los lenguajes se entremezclan, la esencia de una pintura "pura", "sacra", "perfecta" es perecedera desde su misma concepción. Los estudios de Cézanne sobre la virtualidad del mundo -o visiones fragmentadas del espacio- no tienen que ser, por obligación académica, referentes directos de la pintura académica francesa; las tendencias posteriores de los años sesenta: el pop, el minimalismo, el arte povera, el arte conceptual son, entre muchas otras cosas, esquemas alternativos de pensamiento.

La ingerencia de nuevas tecnologías, de irracionalidades provenientes de racionalidades instrumentales, más la contingencia del mundo, son parte de un cambio en la concepción de la materialidad del arte. Según Danto, con la llegada de la filosofía al arte -relación tan antigua como la misma escritura- hacer que la existencia de un objeto, ya sea en un museo, una galería, un parque, una casa, no sea necesaria cuando nunca lo fue. El "descubrimiento" frágil de Danto aboca por la 
modificación, en el sentido de irrelevante, de la institucionalidad del arte, cuando el arte fundamentalmente se encuentra en la acepción discursiva de una narrativa universal ${ }^{7}$.

Así que podemos ir estableciendo el arte como medio de introducción intempestiva en lo real, por medio del hacer humano, abstracto en su producción, concreto en su materialidad y crítico en su pensamiento.

A la larga no trataremos de obstaculizar más el camino discursivo de las artes, no importa sus formas de producción ni su legitimidad institucional -por el momento- abocándonos a no permitir que el discurso del fin se aproxime a deslegitimar uno de los espacios académicos más propensos a generar crítica teórica, por medio de una nueva materialidad del mundo y a no caer en legitimizaciones narrativas como: "después del fin del arte".

Es bastante conocido en la historia de la humanidad que la burguesía se apoderara de la razón -instrumental- convirtiéndola en ideología (Rojas, 2006, p. 133) y, a través de ella, legitimaban discursos que aprisionaban por medio de una distribución y redistribución de cierto número de procedimientos (Foucault, 2002, p.14), la intencionalidad primaria del artista y se sujecionaba al acomodo institucional de disciplinas científicas, como la política o la economía, el quehacer plástico y la obra de arte: "el azar del discurso por medio del juego de una identidad que tendría la forma de la repetición de lo mismo. El principio del autor limita ese mismo azar por el juego de una identidad que tiene la forma de la individualidad y del yo (Foucault, 2002, p. 32) ${ }^{8}$.

La constante revolución de las artes, con respecto a su forma de interpretar el mundo, recrea a modo de re-configuración el cómo conocemos, siendo por necesidad metodología crítica e innovadora, transgresora de toda repetición de lo mismo y rebelde contra toda simplificación epistemológica.

Ahora puede quedar demostrado -y en concordancia con Adorno- que nada referente al arte es evidente. Cuando una sociedad no deja lugar para el arte, y se asusta o actúa de manera indiferente contra este, es el arte mismo el que se encarga de mostrar los "monstruos" de la razón instrumental, que escinden una posesión cultural degenerada y cosificada (Adorno, 1969), cuyo objeto artístico

7 Entiéndase universo en su sentido de universalidad no como "uno" sino como diversidad del todo.

8 La negrita no es del texto original pero sí la exaltación de las palabras. 
se desvanece ante la autoridad del comprador. El placer subjetivo que la obra de arte genera se aproximaría al estado de quien ha sido arrojado del ámbito de lo empírico, como totalidad de interferencias (Adorno, 1969), pero no a lo empírico mismo, es decir, a un desarrollo sensitivo de un tabú social. 


\section{Referencias}

Adorno, T. (1969). Teoría estética. Recuperado de: www.archivochile.com/ideas. Ayer, A.J (1986). El positivismo lógico. México DF: Fondo de Cultura Económica. Benjamín, W. (1936). La obra de arte en la época de su reproductibilidad técnica. Transcritas por Andy Blunden 1998; a prueba y corregido febrero de 2005. Estados Unidos: UCLA School of Theater, Film and Television.

Danto, A. (1999). Después del fin del arte. Barcelona: Paidós.

Foucault, M. (2002). El orden del discurso. (2 $2^{\mathrm{a}}$ ed.). Traducido por: Alberto González Troyano. Barcelona: Fábula.

Hegel, G.W.F (1989). Lecciones de estética. (Vol. 1). Traducción de Raúl Gabás. Barcelona: Ediciones península historia/ciencia/sociedad. Transcribed by Andy Blunden 1998.

Kuhn, T. (1971). La estructura de las revoluciones científicas. México: Fondo de Cultura Económica.

Rojas Osorio, C. (2006). La ciencia como lenguaje. Colección Prometeo 35. Heredia: Facultad de Filosofía y Letras, Universidad Nacional: EUNA.

Rocca, A. (2006). El giro estético de la epistemología. La ficción como conocimiento, subjetividad y texto. Revista Aisthesis (39).

Santos, B. (2003). Crítica a la razón indolente. Contra el desperdicio de la experiencia. Bilbao: Descleé de Brower. 